\title{
SURGICAL RESULTS OF DROPPED NUCLEUS OR IOL
}

KEY WORDS:

\section{Dr Kruti Shroff}

\section{Dr Abhishelk}

\section{Chauhan}

\section{Dr Sahara Tandel}

PURPOSE: To evaluate visual outcome of patients who underwent pars plana-vitrectomy for dropped nucleus or IOL (IOL). METHOD: This prospective study was performed on patients who underwent pars-plana vitrectomy for dropped nucleus or IOL. Data on demographics, preexisting eye condition, surgery details of cataract and vitrectomy, presenting symptoms, interval between cataract surgery and vitrectomy, secondary IOL implanted or not, details of follow-up visits, and postoperative complications were noted. The corrected VA, IOP (IOP), SLE (SLE) and fundus evaluation was done during each visit and was included in statistical analysis.

RESULTS: Out of the 56 patients, 40 cases following cataract surgeries, included 20 cases of nucleus drop and 20 cases of IOL drop. In post-traumatic group, 13 cases were of nucleus drop and 3 cases of IOL drop. All the patients had undergone 3 ports standard pars plana-vitrectomy with or without secondary IOL implantation. ACIOL in 22 cases, SFIOL in 8 cases, while 26 patients were kept aphakic. Out of 56 patients $32.14 \%$ patient hadVA (VA) of more than or equal to $6 / 18,32.14 \%$ with VA $<6 / 18$ but $>6 / 60$ and $35.71 \%$ hadVA $<6 / 60$. Mean post-operative VA of post-operative group was 1.17 and posttraumatic group was 1.49. Major cause for poor visual outcome included corneal decompensation (21.42\%), secondary glaucoma (5.35\%) and $\mathrm{RD}(\mathrm{RD})(1.78 \%)$.

CONCLUSION: Dropped nucleus or IOL following cataract surgery or trauma is a severe complication, but appropriate and timely management can restore VA.

\section{INTRODUCTION:}

The lens is a vital refractive element of human eye. In 2002, the World Health Organization estimated that lens pathology (cataract) was the most common cause of blindness worldwide. ${ }^{1}$ Not surprisingly, cataract surgery is the most common surgical procedure performed in developed world ${ }^{2}$

A Mathai, R Thomas et al in 1999 found that incidence of nucleus drop into vitreous was $0.8 \%$. Incidence for experience surgeon was $0.3 \%$ and for those learning was $1.23 \%{ }^{5}$

Associated clinical signs, which improved gradually, included corneal edema, glaucoma, uveitis, and vitreous opacities. However, other complications such as RD causing profound visual loss were also seen ${ }^{6-8}$.

\section{OBJECTIVE}

The primary objective of study is to evaluate visual outcome of patients who underwent pars-plana-vitrectomy for posteriorly dislocated lens nucleus or IOL, to compare outcomes between surgeries that followed traumatic and non-traumatic etiology and to evaluate incidence of complications.

\section{MATERIALS AND METHODS}

This prospective study was conducted at Tertiary Eye Hospital, from August 2012 to July 2014.

\section{Inclusion Criteria}

All patients of age more than 20 years, having dropped nucleus or dropped IOL following cataract surgery or blunt trauma

\section{Exclusion Criteria}

- Only cortical fragment without nucleus material

- Any pre-existing macular or retinal pathology, glaucoma, uveitis, RD

- Penetrating ocular trauma

- Traumatic glaucoma

- previousPPV

\section{Preoperative Assessment}

History including demographic data, preexisting eye disease, details of previous cataract surgery, and IOL implantation, history of trauma.

Complete ophthalmic examinations which included best corrected VA(BCVA) using Snellen chart at a distance of 6 meter, IOP measurement, SLE to look for peri-limbal injection, corneal edema, anterior chamber reaction, hyphaema, hypopyon, retained lens matter or vitreous in anterior chamber, state of the vitritis, indirect ophthalmoscopy to check for approximate size, number, location and mobility of nuclear fragments in the vitreous cavity, vitreous haemorrhage, retinal tear, $\mathrm{RD}$, cystoid macular edema, and choroidal effusion, etc., SLE with 90D lens especially for macular status.

In cases where fundus was not visible, B-scan was performed.

A-scan for bio-metry, special investigation like specular microscopy was done.

\section{SurgicalTechnique}

- All surgeries were performed under local anesthesia.

- Standard 3-ports (23 guage) pars-plana-vitrectomy was procedure of choice.

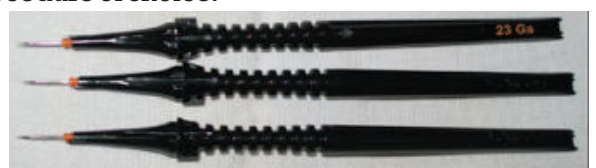

- Central and peripheral vitrectomy was performed to avoid jabbing the vitreous during aspiration.

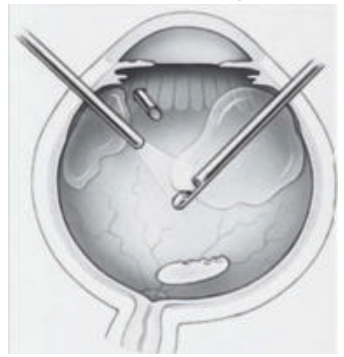

A: Attention To Complete Central Vitrectomy Allows Access To Retained Lens Fragments 


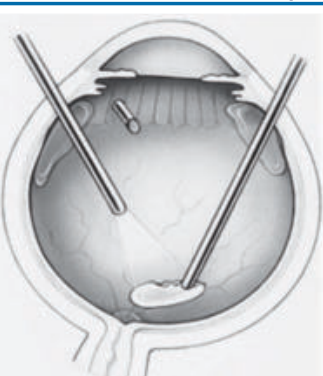

B: Low Ultrasonic Fragmentation Power Allows More Controlled Removal Of Fragments.

- The density of nuclear fragments was re-assessed. Soft remnants were removed with vitreotome. Trapping/ lifting/releasing maneuvers had to be repeated leaving small fragments, which were removed by vitreotome.

- The surgical procedure for dropped IOL was same till vitrectomy. After that the anterior chamber and the section were cleared of vitreous. Later the adhesions around IOL were released and brought into anterior chamber using intra-vitreal forceps, and then was removed.

- Examination of peripheral retina was done. If possible IOL implantation (ACIOL, scleral fixation) was done.
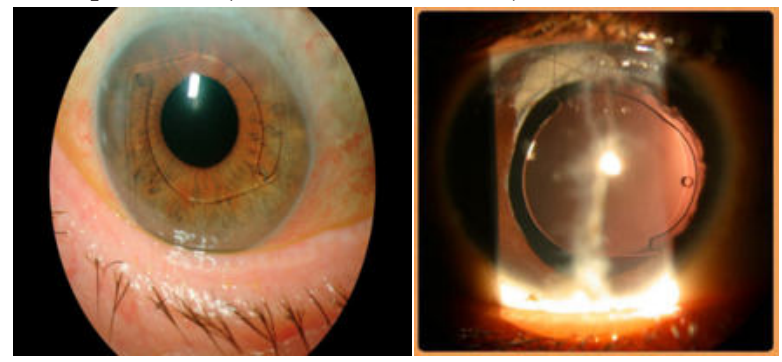

Post-operative Asssessment

- There was a follow-up control of the patients on $1^{\text {st }}$ postoperative day, $1^{\text {st }}$ week, $6^{\text {th }}$ week thereafter.

- The best correctedVA, IOP, SLE and fundus evaluation was done at each visit and included in the statistical analysis.

- Any complications if present were recorded.

\section{Outcome Measure}

The primary outcome measure was gain in BCVA. A poor visual outcome was defined as aVA worse than $6 / 18$.

\section{RESULTS}

A clinical case series conducted on 56 eyes of 56 patients who underwent Pars-plana-vitrectomy at a tertiary care eye hospital.

Out of 56 patients, there were 39 males and 17 females, with mean age being $60.10( \pm 13.05)$ years.

\section{Epidemiological Data}

\section{Table 1: Sex Distribution}

\begin{tabular}{|l|l|}
\hline SEX & No. \\
\hline MALE & $39(69.64 \%)$ \\
\hline FEMALE & $17(30.35 \%)$ \\
\hline TOTAL & 56 \\
\hline
\end{tabular}

Table 2: Age Distribution

\begin{tabular}{|l|l|}
\hline AGE GROUP & No. \\
\hline $21-40$ & 4 \\
\hline $41-60$ & 25 \\
\hline $61-80$ & 24 \\
\hline$>80$ & 3 \\
\hline
\end{tabular}

Table 3 Type Of Drop

\begin{tabular}{|l|l|l|l|}
\hline TYPE & NUCLEUS DROP & IOL DROP & TOTAL \\
\hline POST-OPERATIVE & 20 & 20 & 40 \\
\hline POST-TRAUMATIC & 13 & 3 & 16 \\
\hline
\end{tabular}

\begin{tabular}{|c|c|}
\hline $33(58.92 \%)$ & \begin{tabular}{|l|l|}
$23(41.07 \%)$ & 56 \\
\end{tabular} \\
\hline \multicolumn{2}{|l|}{ Table 4:Type Of Cataract Surgery } \\
\hline TYPE OF CATARACT SURGERY & No. \\
\hline PHACO & $20(46.51 \%)$ \\
\hline SICS & $23(53.48 \%)$ \\
\hline TOTAL & 43 \\
\hline
\end{tabular}

Table 5:secondary Iol Implantation

\begin{tabular}{|l|l|}
\hline POST-OPERATIVE IOL STATUS & No. \\
\hline ACIOL & 22 \\
\hline SFIOL & 8 \\
\hline APHAKIC & 26 \\
\hline TOTAL & 30 \\
\hline
\end{tabular}

- Comparison between pre-operative and post-operative values in individual groups was analyzed using PAIRED T TEST (in data following normal distribution) and WILCOXON MATCHED PAIRS TEST (in data not following normal distribution).

- Comparison between two different groups was analyzed using Mann-Whitney test

- " $p$ "value $\leq 0.05$ was considered statistically significant.

Table 6: Mean Change In Va (logmar) OfTotal Cases \begin{tabular}{|l|l|l|l|}
\hline PARAMETER & PRE-OPERATIVE & POST-OPERATIVE & P VALUE \\
\hline
\end{tabular}

\begin{tabular}{|l|l|l|l|} 
& MEAN VALUE & $\begin{array}{l}\text { (6 } 6^{\text {TH }} \text { WEEK) } \\
\text { MEAN VALUE }\end{array}$ & \\
\hline V/A & 2.30 (SD 0.45) & 1.20 (SD 0.86) & $<0.0001$ \\
\hline
\end{tabular}

- Table 6 shows that improvement in mean VA is statistically significant at $6^{\text {th }}$ week follow up period.

Table 7: Comparision Of Final V/a Between Post-operative And Post-traumatic Cases

\begin{tabular}{|l|l|l|l|}
\hline & $\begin{array}{l}\text { POST- } \\
\text { OPERATIVE }\end{array}$ & $\begin{array}{l}\text { POST- } \\
\text { TRAUMATIC }\end{array}$ & "p" VALUE \\
\hline $\begin{array}{l}\text { MEAN V/A } \\
\text { AT 6 WEEKS }\end{array}$ & $1.17(0.85)$ & $1.49(0.95)$ & 0.3756 \\
\hline
\end{tabular}

- Both groups had improvedVA at $6^{\text {th }}$ week with no significant difference.

Table 8: Comparision Of FinalV/a Between Aciol And Sfiol

\begin{tabular}{|l|l|l|l|}
\hline & ACIOL & SFIOL & P VALUE \\
\hline $\begin{array}{l}\text { MEAN V/A } \\
\left(\mathbf{6}^{\mathrm{TH}} \text { WEEK POST-OP) }\right.\end{array}$ & $0.60(0.34)$ & $1.15(1.14)$ & 0.8670 \\
\hline
\end{tabular}

- No significant difference was found in final visual outcome in patients having ACIOL and SFIOL.

Table 9: Post-operativeVa

\begin{tabular}{|l|l|l|l|l|}
\hline $\begin{array}{l}\text { POST- } \\
\text { OPERATIVE } \\
\text { IOL STATUS }\end{array}$ & \multicolumn{2}{l|}{$\begin{array}{l}\text { POST-OPERATIVE VA (AT 6 } \\
\text { WEEK) No. }\end{array}$} & TOTAL \\
\hline & $\begin{array}{l}\text { TH } \\
(6 / 6-6 / 18)\end{array}$ & $\begin{array}{l}0.6-1(6 / 24- \\
6-/ 60)\end{array}$ & $\begin{array}{l}<1.82 \\
(<6 / 60)\end{array}$ & \\
\hline ACIOL & $13(59.09 \%)$ & $8(36.36 \%)$ & $1(4.54 \%)$ & 22 \\
\hline SFIOL & $4(50 \%)$ & $1(12.5 \%)$ & $3(37.5 \%)$ & 8 \\
\hline APHAKIC & $1(3.84 \%)$ & $9(34.61 \%)$ & $16(61.53 \%)$ & 26 \\
\hline TOTAL & $18(32.14 \%)$ & $18(32.14 \%)$ & $20(35.71 \%)$ & 56 \\
\hline
\end{tabular}

Table 10:Mean Change In Specular Count (cd)In Patients With Secondary IolImplantation

\begin{tabular}{|l|l|l|l||}
\hline $\begin{array}{l}\text { TYPE } \\
\text { OF IOL }\end{array}$ & $\begin{array}{l}\text { PRE-OPERATIVE } \\
\text { MEAN VALUE }\end{array}$ & $\begin{array}{l}\text { POST-OPERATIVE (6 } \\
\text { WEEK) MEAN VALUE }\end{array}$ & P VALUE \\
\hline ACIOL & $\begin{array}{l}\text { 2005.5 (SD } \\
266.50)\end{array}$ & 1966.18 (SD 248.70) & 0.0003 \\
\hline SFIOL & $\begin{array}{l}\text { 1869.25 (SD } \\
469.02)\end{array}$ & 1815.87 (SD 454.32) & 0.0185 \\
\hline
\end{tabular}
\begin{tabular}{|l|l|l|l|}
\hline CD $11:$ Change In Specular Count: Aciolvs Sfiol \\
\hline $\begin{array}{l}\text { POST-OPERATIVE } \\
\left(6^{\text {TH }} \text { WEEK) MEAN VALUE }\right.\end{array}$ & $\begin{array}{l}\text { 1966.18 } \\
\text { (SD 248.70) }\end{array}$ & $\begin{array}{l}\text { 1815.87 } \\
\text { (SD 454.32) }\end{array}$ & 0.2546 \\
\hline
\end{tabular}


- Post-operatively, there was significant change in density of endothelial cells at $6^{\text {th }}$ week. However, Comparison of reduction was statistically found insignificant.

Table 12: Post-operative Complications

\begin{tabular}{|l|l|}
\hline COMPLICATIONS & No. $(\%)$ \\
\hline CORNEAL OEDEMA & $12(21.42 \%)$ \\
\hline SECONDARY GLAUCOMA & $3(5.35 \%)$ \\
\hline CME & $1(1.78 \%)$ \\
\hline RD & $1(1.78 \%)$ \\
\hline OPTIC ATROPHY & $1(1.78 \%)$ \\
\hline TOTAL & $18(32.14 \%)$ \\
\hline
\end{tabular}

No cases of endophthalmitis were noted

\section{DISCUSSION}

With advent of phaco-emulsification, there has been an apparent increase in the occurrence of retained lens fragments post-surgery. Review of the literature indicates lack of consensus regarding what effect the timing of PPV has on visual outcome.

- VA improved in all of our patients who underwent 23-G vitrectomy. $32.14 \%$ of eyes achieved a final acuity of $6 / 18$ or better. Compared to the study done by Ali salehi, ${ }^{1}$ Hassan Razmju, et al, in which they achieved final VA better than $6 / 18$ in $42 \% .{ }^{10}$ Oruc $S$, et al achievedVA of $6 / 18$ or better in $51.8 \% .^{14}$

- In our study there were no significant changes in final VA following PPV among post-operative and post-traumatic groups with mean gain in VA of 1.17 and 1.49 respectively at 6 weeks follow up time, similar to study done by Shah MA, Shah SM, et al $(\mathrm{p}=0.606)^{15}$

- About $59.09 \%$ of patients with ACIOL and $50 \%$ patients with SFIOL had improved good VA of more or equal to $6 / 18$, showing that type of IOL did not influence the visual outcome.This was supported by Oruc S, et al. ${ }^{14}$

Among SFIOL group 3(37.5\%) had poor visual outcome of $<6 / 60$. This is because of the complications like $\mathrm{RD}$, postoperative optic atrophy and corneal decompensation. Aphakic patients had poor visual outcome of $<6 / 60$ in $61.53 \%$,. Main cause of poor outcome was corneal oedema with corneal decompensation(75\%) and secondary glaucoma(12.5\%).

- The density of endothelial cells decreased postoperatively ( $6^{\text {th }}$ week follow up period), showed insignificant difference ( $p$ value 0.2546 ) in endothelial cell loss between ACIOL and SFIOL at day 30 . This correlation is not well mentioned in literature.

- Major cause of poor visual outcome in our study was corneal decompensation. With the incidence of postoperative complications, which included persistent corneal edema(21.42\%), secondary glaucoma(5.35\%), $\mathrm{CME}(1.78 \%)$ and $\mathrm{RD}(1.78 \%)$. While Kyung Min Koh, Hyoung Seok Kim, et al presented complications like elevatedIOP(13.8\%)and CME $(2.7 \%)^{9}$.

Oruc $\mathrm{S}$, et al noted RD incidence of $8.2 \%$, it was $4.95 \%$ in Borne $\mathrm{MJ}$ et $\mathrm{al}^{16}$ and $4.1 \%$ in Zafar S, et $\mathrm{al}^{13}$. While we noted only l patient $(1.78 \%)$.

CME was found in only 1 case $(1.78 \%)$, while Pedro Romero-Aroca, et al found $31.91 \%{ }^{11}$ incidence of CME. Mean follow up in our study only 6 weeks which is a study limiting factor when compared to other studies as they have longer follow up.

\section{CONCLUSION}

- FinalVA was significantly improved after PPV for nucleus/ IOL drop.

- Most common complication associated with PPV for dropped nucleus or IOL was persistent corneal edema.

- Prompt removal of lens matter by Pars-plana-vitrectomy and management of postoperative complications can ensure good visual outcome for the patient.

\section{REFERENCES}

1. Foster A:The impact of Vision 2020 on blindness. Eye 2005; 19:1133 1135 .

2. Allen D:Cataract and surgery for cataract. BMJ 2006;333:128-132.

3. Learning DV.Practice style and preferences of ARCRS member 1994 Survey.J Cataract Refract Surg 1995;21:378-85.

4. Pande M. Incidence of lens matter dislocation during phacoemulsification. J Cataract Refract Surg 1996;22:737-42.

5. Incidence and management of posteriorly dislocated nuclear fragments following phacoemulsification. Indian J Ophthalmol 1999;47:173-6

6. Irvine SR:Lens-induced uveitis and glaucoma.Ophthalmol 1958;60:829-840.

7. Diagnosis and management of lens-induced glaucoma. Ophthalmology 1982;89:227-230.

8. Blodi BA, et al: Retained nuclei after cataract surgery. Ophthalmology 1992; 99:41-44.

9. Borne MJ, et al: Outcomes of vitrectomy for retained lens fragments. Ophthalmology 1996; 103:971-976.

10. Dropped Nucleus Following Phacoemulsification Cataract Surgery. Med J Malaysia 2007;62:364-367

11. Management of nucleus loss into the vitreous: long term follow up in 63 patients. Clin Ophthalmol 2007; 1(4):505-512.

12. Surgical outcome of 23-gauge vitrectomy for the management of lens fragment dropped into the vitreous cavity during cataract surgery. Saudi J Ophthalmol. Oct 2014;28(4):253-256.

13. Visual outcome of pars-plana-vitrectomy for dropped nucleus after phacoemulsification.J Coll Physicians Surg Pak 2012 Jun;22 (6):367-70.

14. outcome of vitrectomy for retained lens fragment after phacoemulsification. Ocul Immunol Inflamm 2001 Mar;9(1):41-7.

15. Shah $\mathrm{MA}^{*}$, et al., (2014). Comparative study of visual outcomes following corrective vitrectomy:Int J Ophthalmol Eye Res.02(8), 1-4.

16. Machemer R. Vitrectomy: a pars plana approach. Technical improvements and further results.Acad Ophthalmol Otolaryngol 1972;76:462-466. 